\title{
Enterprising for Rural Transformation in Developing Countries: The Natural Availability Dilemma
}

\author{
George Muganga ${ }^{1}$, Anthony Mpairwe², Abigail Komurere ${ }^{3}$ \\ Department of Psychology and Development Studies, Bishop Stuart University, Mbarara, Uganda
}

\begin{abstract}
The paper is about entrepreneurship and rural transformation. It highlights the nexus between natural availability of resources and the limited entrepreneurial potential in rural areas in developing countries. While Uganda is used as a reference point, contextual issues raised relate and apply to developing countries world over. The author presents the underlying problems towards enterprising, adduces the evidence to the problems and provides a way forward for managing the root causes. The paper advances the natural availability phenomena as the root cause of a poor enterprising culture in rural areas and uses land abundance and related traditional agricultural practices in rural areas to substantiate the phenomena.The main thesis of the paper is that a great potential for enterprising in rural areas exists but is ironically impeded by the abundance and natural availability of what is required to initiate and implement business ideas. A process-package strategy is advanced as a way forward to igniting an enterprising culture in developing countries.
\end{abstract}

Keywords: Enterprising, Agriculture, Natural Availability, rural areas, processing, packaging

\section{Introduction}

The population of Uganda was projected at 35.8 million people by year 2015 (UBOS, 2014). World Bank (2016) estimates the population at 38.8 million people. According to the 2014 census report $48.1 \%$ of the population is made up of young people aged below 15years, $49.4 \%$ aged between 15 65 years, and $2.5 \%$ aged above 65 years (National Population and Housing Census 2014). Uganda has a high fertility rate which explains why more than half of the population is youthful. This is an indication that Uganda`s population is increasing but in addition is youthful and productive. In principle this is an enterprising opportunity referred to as a demographic dividend (National Planning Authority, 2014). To harness this opportunity requires that the high and excess population is engaged in productive activities. Agriculture is the back born of Uganda`s economy and provides a window for engaging the high population. Available literature points to the fact that between 65 to $80 \%$ of workforce is employed in agriculture but its contribution to economy is far less than the labour employed (Ofwono 2009; UBOS 2008; UBOS 2012). The sector contributes less than $20 \%$ to GDP with the rate of growth below the average 6.5\% GDP and 3.4 population growth rates. This has been the trend over time manifested in high unemployment and low productivity spilling over a poor enterprising culture.

The country is grappling with the challenge of gainfully employing almost half of the population that does not contribute gainfully to GDP (Republic of Uganda, 2014). Most of these are in rural areas and categorized as poor. A study conducted by the country`s Ministry of Finance in 2014 found out that $19.4 \%$ of population was poor, $43 \%$ were not poor but insecure while remaining $37 \%$ were the middle class who are in negative net worth due to high debt burden. Only $0.6 \%$ were classified as rich. According to World Bank (2015), 37.8\% of the population lives on less than 2 dollars per day. A further search reveals that $68 \%$ of the population is non monetised as they are not involved in any formal or registered business.

While this paints a glaring picture about the country especially in rural areas, there have been countless business and economic break through particularly since 1986 when the current National Resistance Movement government took over leadership. Uganda has an exciting entrepreneurial path. It is reported to have the highest new business ownership rate in the world at 28\% and with a Total Early-Stage Entrepreneurial Activity (TEA) index of 36, positioning it as the third top country in Sub-Saharan Africa only after Zambia (41) and Ghana (39) (Balunywa et.al. 2012). TEA index captures the level of dynamic entrepreneurial activity. The same report however shows the country with the highest business discontinuation rate in the world. The Doing business report 2016 ranks Uganda 122 ahead of its Regional neigbhours of Kenya, Rwanda and Tanzania and further notes that Uganda`s percapita Gross National Income is US\$660 (World Bank, 2016). A single digit inflationary rate has been maintained since the NRM government took power. These among other economic advances however, appear to have had little or no trickle-down effect on rural areas and majority of poor people. While agriculture is the main economic activity in rural areas it has not provided the desired entrepreneurial stimulus to development-yet agricultural potential for development is unquestionable. What is more engaging is the fact that conditions for agriculture in most rural areas in Uganda just like most other developing countries are favourable. Uganda`s description as the pearl of Africa is not only about the scenery, natural resources and environment. The environment is conducive for agriculture which largely relies on nature. In rural areas most of what is needed for production is naturally available including land with fertile soils, water, and good climate among others. The natural availability of these however appears to have a dismal trigger effect to enterprising. This is why it is prudent that a synthesis

\section{Volume 6 Issue 12, December 2017}




\section{International Journal of Science and Research (IJSR) \\ ISSN (Online): 2319-7064 \\ Index Copernicus Value (2016): 79.57 | Impact Factor (2015): 6.391}

be made of the effect of nature's generosity or naturally available resources on enterprising culture on rural areas.

\section{Method}

This is a synthesis paper that builds on the experience and plausible views of the authors reinforced by a review of literature. The paper focuses on land as a naturally available resource and agriculture as the common land based activity. Other resources on and beneath land including oil, water, forests are occasionally used for further clarification. It focuses on rural areas in developing countries with Uganda as a reference point.

\section{Results and Discussions}

Uganda's economy is not far from other economies that are struggling with economic growth neither is it unique from those economies which struggled and overcame crippled growth and reached take off stage of development. The Asian tigers including Singapore, Malaysia and Thailand provide a useful case study.

It needs to be noted that majority of the population in Uganda is engaged in agricultural mainly as a means of subsistence. Agriculture in this case sums up all activities that relate to farming including crop and livestock. This practice supplies most of the employable products and services. Take the example of clothes that we put on, food we eat/drink, and household furniture among others. These are land based daily bread requirements with a ready market that in most cases is not restricted. Given that agriculture employs $80 \%$ of the population, one would expect that such a corresponding percentage would not be poor which, is not the case. In any case, agricultural sector contributes around 65\% of GDP less than the $80 \%$ that it employs. The bulk of agriculture contribution is from the large farms, middle men, producers and exporters and not the small subsistence rural farmer- who in this paper is categorized as less or not enterprising compared to the former. Enterprising in this paper is breaking away from the traditional mode of outlook, productivity and lifestyle to seize new opportunities that create better value for improved wellbeing. It is about "thinking out of the box and comfort zone". The emphasis is on making rural areas and people maximally use available nature resources particularly land for gainful employment. The hypothesis is that naturalabundance and availability of resources such as land impedes a productive andan enterprising culture through nurturing a comfort zone in rural areas. The huge expanses of vast land across the countryside, some that have never been touched, favourable climate with a naturally balanced mixture of rainfall, wind and sunshine, natural foods and medicines including fruits, forests and, edible insects and herbs among others attest to this. This is in comparison with the urban counterparts where most of the naturally available output has been value added, improved, duplicated and replicated to ensure stable supply and outflow for mainly commercial purposes. Rural areas continue to use the same resources and methods to meet the same aspiration-subsistence survival. This is much more clearer if you follow agricultural practices irrespective of the market potential available particularly in towns. The issue then is why many people have especially those in rural areas who practice agriculture not been enterprising or not getting out of poverty through agriculture? Many reasons have been exhaustively advanced to this end. The nature of education system that is theoretical, desire for white collar jobs, lack of market, advisory services among others. While these are clearly plausible, they appear not to position the problem in the right perspective. So what is intrinsic about land-agricultural entrepreneurial potential?

It is expressed that the biggest problem to agricultural entrepreneurship that would have transformed rural areas is nature. Nature provides free and fertile agricultural land. This we refer to as natural availability phenomena. In this paper, natural availability refers existence of land and the costless existence of most of what rural people need to practice farming. The focus on land is premised on the assumption that it remains a primary factor of production and a major resource and source of earning in rural areas. There are countless inputs and requirements for farming including seeds, equipment, water, fertilisers among others. All these come from land which makes its critical for farming. It is clear that with increasing population, the amount of land available for farming is reducing. Population theorist Malthus 1798 had hypothesized that man would outstretch lands' natural capacity to supply food leading to a starvation and deathpopulation trap. Such trap is however more likely to happen due to man`s failure to enterprise rather than population boom. The looming land unavailability has been offset through clearance of formerly reserved areas like forests, wetlands and mountain slopes and in rural areas and even then there still exists plenty of land that is either untouched or underutilized. A ride through the country side reveals the extent of the free and untilised land in all developing countries.

Needless to note that the lack of land in a rural setting is a hindrance to agriculture but ironically its natural and free abundance is also a limitation. In general terms land exists in rural areas and most of which is still in its natural fertile state. Uganda for instance is described as country gifted by nature with expanses of arable land and fertile soils that support agro based enterprises; a number of fresh water bodies including the World`s second largest lake that is home to various fish species; a variety of minerals among others (Republic of Uganda, 2015). In addition most of the land in rural areas is inherited and therefore free. Due to this rural people are under no threat as they find themselves amidst chunks of land and only using it to meet the daily short termfood requirements. The daily availability of mainly food adds onto other services like housing, security, sanitation, water which would otherwise be costly in urban areas. Mandatory government levies and deductions like licenses and taxes can be conveniently avoided by the rural folk. This is particularly possible where they avoid the formal trading system save for a few less costly home products like salt and matchbox. This creates both a comfort and blanket zone for rural people. The

Volume 6 Issue 12, December 2017

www.ijsr.net

Licensed Under Creative Commons Attribution CC BY 


\section{International Journal of Science and Research (IJSR) \\ ISSN (Online): 2319-7064 \\ Index Copernicus Value (2016): 79.57 | Impact Factor (2015): 6.391}

blanket zone makes agriculture common and short of enterprising opportunities. Neither land nor agriculture poses innovative dimensions and the practice ends up adopted as a lifestyle rather than a productive asset or activity. The comfort zone makes people satisfied with the status quo and in no way would one become entrepreneurial at that stage. Rural people are contented with status quo and wont venture into unknown territories. This is why most find it uncomfortable to leave their traditional homesteads, start a new business or change a life style.

Therefore even if markets where available which they are or the education system became practical which is the case in the perspective of agriculture in rural areas, the possibility of agribusinesses and enterprises will remain limited as long as no threat, severity or force exists. This is because the motivation to enterprise is mostly due to competition, necessity to survive and challenge to existence. In rural areasthese are rarely experienced save for unexpected disaster and unfavorable weather resulting in landslides, floods, prolonged dry spells among others. The urge to enterprise is curtailed by the perception of natural availability. Poverty largely associated with rural areas would have been a better wakeup call or igniter but is neither a threat nor a challenge rather a blanket zone that becomes an excuse for inactivity rather than creativity. The abolition of graduated tax in Uganda in 2005 provides a good reference point. While the tax was largely discredited as unpopular, uneconomical therefore undesirable (Sewanyana and Okidi, 2008), little seen were the consequences of comfort-people not paying tax from what they earn. It has been argued that as a result some men have resorted to binge drinking and sports betting (New Vision, 2016). Initially the pressure to pay the tax-severity would make one think beyond food availability. During that time when the tax was levied, many people used to work harder at least to raise the tax. It needs mention that hardworking and enterprising are closely related in the sense that one leads into the other. Today, the life style in rural areas is changing from work to gambling, drinking, and stealing. The increasing casinos and betting centers for games like pool, cards, sports betting, televised soccer attest to this. Such is the line in which productivity and creativity termed as enterprising reduce.

\section{Natural availability as an impeding factor}

Evidence from studies, conditions and countries that have prospered amidst limitations in general and specifically limited agricultural land and harsh climate, limitations in options of survival and necessity provides the basis of analysis. In any case, necessity and survival account for most of thehuman kind innovations. Stone Age blacksmiths had to invent fire as a necessity for they would not have survived physically and economically and in so doing fabricated metals that would guarantee both food and personal security. The extremely cold winter in Europe in 1600s that resulted in deaths of millions of people could not exterminate the human race and resulted into high levels of creativity and innovations for survival. The East Asian economies of Japan, Korea, Taiwan, Singapore and Hong Kong achieved western-level standards of living despite being rocky islands (or peninsulas) with virtually no exportable natural resources (Binal et.al. 2013). Developed countries including Japan, Russia and Israel among others are not necessarily naturally gifted agricultural territories but very industrious in agricultural terms. Israel is characterized by rocks and an environment that is not conducive for natural agriculture. Ironically it is selfsufficient and exports food largely because of a changed mindset that sees rocks as soil, dry as wet lands and threats as opportunities.In Japan a highly developed economy, people are dying of overwork, stress and failure to hit life targets more than comfort, relaxation and less work. In these countries it is not technology that has improved productivity rather threat to survival. Green house farming, irrigation, genetically modified crops, mechanisation are some of the advances by naturally un-gifted areas to cope with their difficult environment. Such advances are not due to riches but threat to survival which is the reverse in developing rural areas. In such rural areas for instance, it is common knowledge that planting seasons are during rainy days. People will wait to plant only when it rains and harvest when it shines compared to developed regions. In addition the climate and weather are favorable adjusting for the farmer rather than vice versa. Natural resources like forests, water are either less utilised or overutilised until nature provides an alternative or replacement. This is why prolonged droughts result into hunger and starvation. In comparison, countries with neither rain nor sunshine produce food throughout the year.

This is not to say that there is no need for natural resources at least their availability. The importance of availability of resources cannot be under estimated. The huge oil resources in the Arab rentier states, Norway, America among others, Latin America's and Democratic Republic of Congo's natural forests, South Africa`s gold, South Sudan`s land amongothers, have been critical to the countries' economies. There is however plenty of evidence about the strong correlation between natural resource abundance and poor economic growth (Sachs and Warner 1995; 2001, Behbudi 2010; Abott 2014). In most of these studies the analysis is that natural abundance creates comfort for inefficiency and unsustainable use resulting into extinction or scarcity. Scarcity however could largely be perceptional. In a survey of economics of natural resource availability, Nuermayer (2000) however coins the term resource optimists creed to dispel the worry about extinction and explains the critical importance of resources but also and how man is likely to play around a scarce resource to guarantee productivity at all times. His analysis that resources will always be scarce points to perception rather than physical available. Therefore even in cases where resources are abundant, they may viewed as scarce and vice versa. Given that the propensity to optimize and positively tap into resources particularly by rural and developing areas is low, it is most certain that the most abundant resources will remain scarce. This has already been experienced in most if not all African countries with huge oil reserves. In countries like Chad, Nigeria, South Sudan, oil is "scarce" and more expensive. It is a curse instead of a blessing and this applies to forests of Congo, gold of Angola, land of Uganda etc. This is

Volume 6 Issue 12, December 2017

www.ijsr.net

Licensed Under Creative Commons Attribution CC BY 


\section{International Journal of Science and Research (IJSR) \\ ISSN (Online): 2319-7064 \\ Index Copernicus Value (2016): 79.57 | Impact Factor (2015): 6.391}

can be explained from the terrible history of wars and conflict in such countries and probably the situation would have been different without such natural resources. Other authors have referred to such abundance as winners curse, and paradox of plenty among others (Auty 2001; Binal et.al. 2013). While this reference has made been made to the oil resource, it equally applies to land and consequently agricultural practice on such land. Comfort zones therefore make people less innovative, generally chaotic and this partly explains why rural areas in Uganda just like those in other developing countries remain behind.

\section{Way forward-Process package strategy}

In light of the manifestations shared, it is clear that becoming enterprising needs to be conditioned and enforced rather than encouraged. The state should therefore be at the helm of creating environments that challenge people to enterprise and to shift from subsistence survival to creativity and commercial viability. This in principle calls for robust and sometimes autocratic transformational policies and programs.

A myriad of approaches exist to rural transformation through natural availability. While they appear diverse, they all converge to one thing-productivity and commercialisation of nature or artificial availability. This primarily means attaching a standard and cost to everything that relates to nature that was hitherto freely and naturally available. This includes costing land and related input, process and output of such land. The paper proposes a compulsory Process and Package (PP) strategy which can be interpreted as industrialization strategy to development-the only difference being on scope, focus and methodology. Industrialisation aims at producing finished products and processing and packaging are vital stages of production. They are however also independent strategies as not everything that is processed or packaged is part of the industrial process. In this case PP is adopted as an independent strategy though it may translate into industrialization. It implies processing and packaging the hitherto unpackaged naturally available resources and goods. The strategy focuses on use and production of output in a manner that follows clearly laid down standards by the state that guarantee quality particularly for storage and marketability. The thesis is that rural areas would be more enterprising if all that is naturally available gets processed or packaged.

How can naturally available land and related output be processed and packaged? While land can be processed through plotting, surveying and acquiring the title referred to as registration in Uganda, the focus of this paper is on the latteroutput. The argument is that the best way of processing naturally available agricultural land is processing the output. The PP system would itself dictate that land which produces such output goes through a standard system before, during and after use. The effect of processing and packaging agriculture output has far reaching implications on land availability, use and entrepreneurship. First, PP demystifies the essential tenets of free availability. By its nature, PP is business oriented and not only improves the quality of the product but implies that payment is made to recover whatever was used. It also implies that the entrepreneur who in this case processes and packages ensures that naturally available land which was previously viewed as freely productive is now seen as part of the process of generating funds. Land is then treasured and invested in to increase productivity so as to support large scale output for the PP agenda but also recoup initial investment. This inherently raises the possibility of innovation and use of advanced technology.

The strategy works through government regulations that ban or make it unviable to sale or consume unprocessed and unpackaged agriculture products which are the mainstay of rural areas. This leaves the only option of Processing and Packaging. This has been practiced by governments world over, the difference lies in scale and rationale. In most cases, governments have been enforcing such so as to guarantee safety and quality rather than improving productivity, entrepreneurship or even industrialization. If this is to work, regulations would require that all that is consumed in rural areas including water, milk, fruits, meat among others would need to be either processed, packaged or both. The postulation is that not everyone who possesses free land would be able to use it for gainful processing or packaging. People would opt for other economic activities where they stand a better chance of survival. There would be those who decide to farm and produce for processors, others would rent their land physically or through construction while some would stick to the rules by processing and packaging. Individuals or their groups threatened by competition are likely form cooperative societies to have a bigger voice. The remaining would opt out of farming and land related activities altogether, sell their land and venture into after processing and packaging stages of land based output or completely new areas including services and products like consultancy, tourism, synthetics among others. Therefore more pay services and products would replace formerly freely traditional activities.

A fundamental issues lies on enforcement of the PP strategy. There exits output that may be difficult to process, package or enforce particularly in rural areas. This includes naturally available and free resources like water; sunshine; wind and homemade and produced output not meant for sale. Ironically these must be targeted as they are responsible for creating the convert zone that stalls the enterprising culture. As for naturally available resources, these have traditionally been controlled by the state. The state only needs to expedite control of such resources. Take the example of lake or river water, the state would tighten control in a way that its use would require express permission and follow-up, ban or restrict use completely. This is compared to the traditional open access of such resources. This however requires that the state also provides better and cheaper alternatives through water extension and supply of processed water at sources of natural water among others.

In the case of farm or home produce the state should set up a deliberate scheme that sets thresholds of what does or does not qualify for processing and packaging, institute taxes targeting

\section{Volume 6 Issue 12, December 2017}




\section{International Journal of Science and Research (IJSR) \\ ISSN (Online): 2319-7064 \\ Index Copernicus Value (2016): 79.57 | Impact Factor (2015): 6.391}

farming stages with a refund once evidence of processing and packaging the output/production as per set standards is adduced. In addition to restrictions, incentives are used to support and entice rural areas into processing including free market zones, stable and affordable power supply, health and education insurance among others.

In all this, the thought of innovation for business and competition in rural areas in Uganda just like other developing countries would be stronger than for subsistence. With PP strategy, the end result is that lifestyle in rural areas would be more enterprising, productive, business oriented and engaging, resulting into transformation and progress.

\section{References}

[1] Auty, Richard. M, 2001. Resource abundance and economic development. Oxford University Press.

[2] Balunywa, Waswa., Peter, Rosa., Samuel, Dawa., Rebecca, Namatovu., Sarah, Kyejjusa., Diana, Ntamu, 2012. GEM Uganda 2012 Report. Global Entrepreneurship Monitor, Kampala Uganda

[3] Behbudi, Davood.,Siab, Mamipour and Azhdar. Karami, 2010.Natural Resource Abundance, Human Capital and Economic Growth in the Petroleum Exporting Countries. Journal of Economic Development 81, Volume 35, Number 3, September 2010

[4] Bimal, Chandra. Roy.,Satyaki, Sarkar., Nikhil, Ranjan. Mandal, 2013. Natural Resource Abundance and Economic Performance-A Literature Review. Current Urban Studies 2013. Vol.1, No.4, 148-155.Available: http://www.scirp.org/journal/cus, Date Accessed 3rd December 2016

[5] Murshed, S. Mansoob, 2004. When does natural resource abundance lead to a resource curse? EEP Discussion Paper 04-01. International Institute for Environment and Development, London.

[6] National Planning Authority, 2014. Harnessing the demographic dividend; accelerating socioeconomic transformation in Uganda.Policy brief, July 2014, Kampala Uganda.

[7] NewVision Newspaper, 2016. Government rejects calls to reintroduce Graduated Tax. 23rd April 2015, 11:45 PM.

[8] Nuemayer, Eric, 2000. Scarce or abundant? The economics of natural resource availability. London School of Economics and Political Science. Journal of Economic Survey, Vol 14. No 3. Blackwell Publishers Ltd

[9] Ofwono, Nelson .F. O, 2000. Farmer Entrepreneurship In Uganda.Agri-Profocus Synthesis Paper, October 2009

[10] Republic of Uganda, 2014. Harnessing the Demographic Dividend, Accelerating socio economic transformation in Uganda. The National Planning Authority, Kampala, Uganda

[11] Republic of Uganda, 2015. Uganda Micro, Small and MediumEnterprise (MSME) policy. Ministry of Trade, Industry and Cooperatives. Kampala, Uganda

[12] Sachs, Jeffrey., Warner, Andrew, 1995. Natural Resource Abundance and Economic Growth. NBER Working Paper (5398).
[13] Sachs, Jeffrey. D., Andrew. M. Warner, 2001. Natural Resources and Economic Development. The curse of natural resources" European Economic Review 45, 2001, pp 827-838.

[14] Sarah, N. Ssewanyana and John. A. Okidi,2008. A micro simulation of the Uganda tax system (UGATAX) and the poor from 1999 to 2003. Research Series No. 55, October 2008, Economic Policy Research Centre (EPRC), Makerere University Kampala.

[15] Uganda Bureau of Statistics, 2012. Agricultural Sector Gender Statistics Profile. Statistics House, Kampala Uganda

[16] World Bank. (2015). Uganda systematic country diagnostic. Boosting Inclusive Growth and Accelerating Poverty Reduction. Report No: 97145-UG

[17] World Bank Group, 2016. Doing Business 2016 SubSaharan Africa (SSA). 13th Edition. Washington, DC.

Volume 6 Issue 12, December 2017

www.ijsr.net

Licensed Under Creative Commons Attribution CC BY 